\title{
Pulmonary epithelial-myoepithelial carcinoma without AKT1, HRAS or PIK3CA mutations: a case report
}

\author{
Naoki Yanagawa ${ }^{1 *}$ D, Ayaka Sato ${ }^{1}$, Masao Nishiya ${ }^{1}$, Masamichi Suzuki ${ }^{1}$, Ryo Sugimoto ${ }^{1}$, Mitsumasa Osakabe ${ }^{1}$ \\ Noriyuki Uesugi ${ }^{1}$, Hajime Saito ${ }^{2}$ and Tamotsu Sugai ${ }^{1}$
}

\begin{abstract}
Background: Pulmonary epithelial-myoepithelial carcinoma is a rare subtype of lung cancer. Because of its rarity, the molecular information on this carcinoma is insufficient.

Case presentation: We report a case of pulmonary epithelial-myoepithelial carcinoma without AKT1, HRAS or PIK3CA mutations in a 76-year-old woman. Computed tomography revealed a tumor located in the left lower lung. Thoracoscopic left lower lobectomy was performed. Histopathologically, the tumor consisted of duct-like structures and polygonal and spindle cell features. The duct-like structures were composed of two distinct cell layers. The inner layer consisted of cuboidal cells that were positive for pan-cytokeratin and negative for p63, whereas the outer layer consisted of polygonal and spindle cells that were positive for p63 and weakly positive for pancytokeratin. We evaluated mutations in AKT1, BRAF, CTNNB1, HRAS, KRAS and PIK3CA but did not detect any mutations.

Conclusion: Pulmonary epithelial-myoepithelial carcinoma is a rare subtype of lung cancer, with only 56 previous cases reported in the English literature. The genetic alterations in pulmonary epithelial-myoepithelial carcinoma are still unknown. We examined the 6 genes mutation analysis, however no mutation was detected.
\end{abstract}

Keywords: Pulmonary, Epithelial-myoepithelial carcinoma, AKT1, HRAS, PIK3CA

\section{Introduction}

Epithelial-myoepithelial carcinoma (EMC) is a malignant tumor that occurs mainly in the salivary glands [1]. This tumor also arises in other locations such as the respiratory tract, minor salivary glands and lacrimal glands [1-3]. Primary salivary gland-type tumors of the lung account for $0.1-1 \%$ of all primary lung carcinomas, and the majority are mucoepidermoid or adenoid cystic carcinomas $[4,5]$. EMC is a rare subset of salivary glandtype tumor of the lung, with only 56 cases previously

\footnotetext{
* Correspondence: nyanagaw@iwate-med.ac.jp

${ }^{1}$ Department of Molecular Diagnostic Pathology, Iwate Medical University,

2-1-1 Idaidori, Yahaba-cho, Shiwa-gun, Iwate 0283695, Japan

Full list of author information is available at the end of the article
}

reported in the English literature [6]. Because of its rarity, molecular information on this tumor type is not sufficient.

\section{Case presentation}

A 76-year-old woman was diagnosed with colon carcinoma and underwent preoperative examinations. Computed tomography coincidently revealed a welldemarcated tumor, $1.8 \times 1.3 \mathrm{~cm}$ in size, located in the left lower lung (Fig. 1). She did not have any respiratory symptoms. Laboratory data revealed no significantly abnormal findings. Endoscopic submucosal dissection of the colon carcinoma was performed. Bronchoscopy revealed an endobronchial mass, and 


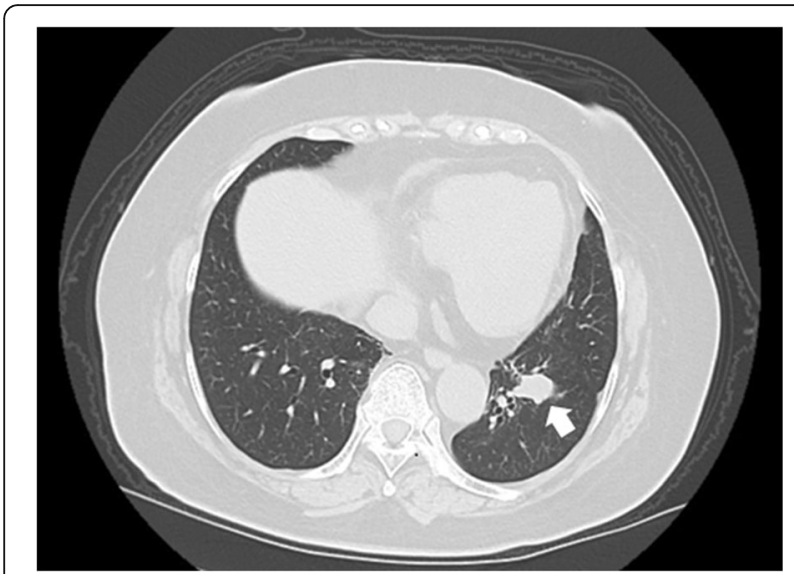

Fig. 1 Computed tomography revealed a well-demarcated tumor, $1.8 \times 1.3 \mathrm{~cm}$ in size, located in the left lower lung (white arrow)

transbronchial biopsy was performed. She was diagnosed with an adenocarcinoma, and thoracoscopic left lower lobectomy with hilar and mediastinal lymph node dissection was performed.

\section{Pathological findings \\ Macroscopic findings}

A specimen containing the tumor was obtained at surgery. Macroscopically, the tumor size was $2.7 \times 1.9 \times 1.8$ $\mathrm{cm}$, and the cut surface of the tumor was whitish-yellow to gray, shiny, and well-demarcated (Fig. 2a).

\section{Histopathological and immunohistochemical findings}

The tumor consisted of duct-like structures and polygonal and spindle cell features (Fig. 2b). The duct-like structures were composed of two distinct cell layers. The inner layer comprised cuboidal cells with eosinophilic cytoplasm and round nuclei, and the outer layer comprised cells with clear cytoplasm and oval nuclei (Fig. 2c). The duct-like structures contained eosinophilic material in the luminal spaces. The polygonal and spindle cells (black arrowhead) were similar to the outerlayer cells (black arrow) (Fig. 2d). There was no necrosis or hemorrhage. Mitotic activity was found ( 2 mitoses/10 high-power fields). Immunohistochemically, the innerlayer cuboidal cells were positive for pan-cytokeratin (Fig. 3a) and negative for vimentin, p63 (Fig. 3b), HHF35 (Fig. 3c), S-100 (Fig. 3d) and TTF-1, suggesting an epithelial phenotype. On the other hand, the outer-layer cells as well as polygonal and spindle cells were positive for p63 (Fig. 3b), HHF35 (Fig. 3c), and S-100 (Fig. 3d), and weakly positive for pan-cytokeratin (Fig. 3a), suggesting a myoepithelial phenotype. Overexpression of p53 protein was not found.

\section{Mutation analysis}

We conducted polymerase chain reaction (PCR) followed by Sanger sequencing and pyrosequencing to investigate the mutation status of the oncogenes associated with EMC of the salivary gland [7]. Briefly, DNA from formalin-fixed paraffin-embedded tissues was

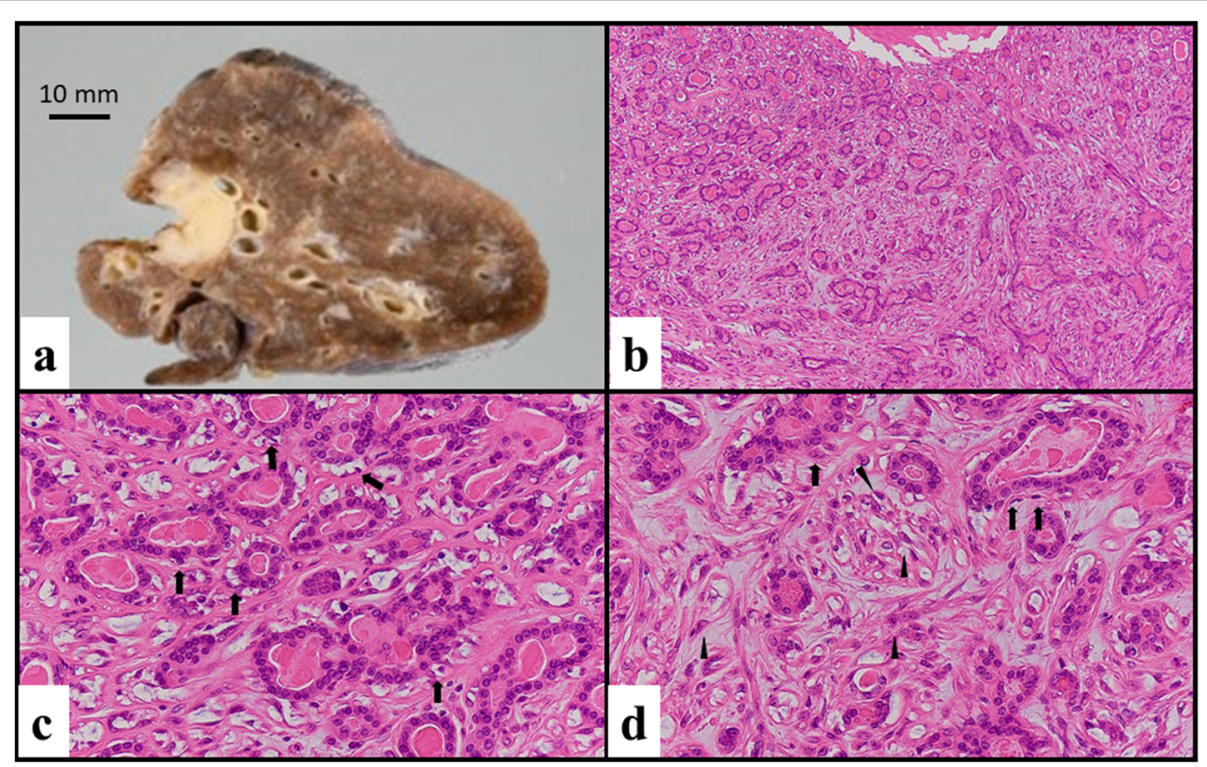

Fig. 2 Macroscopic and microscopic findings. a Cut surface of the surgical specimen. The tumor size was $2.7 \times 1.9 \times 1.8 \mathrm{~cm}$, whitish-yellow to gray, shiny and well-demarcated. $\mathbf{b}$ The tumor consisted of duct-like structures and polygonal and spindle cell features. c The duct-like structures comprised two distinct cell layers. The inner-layer cells were composed of cuboidal cells with eosinophilic cytoplasm and round nuclei, and the outer-layer cells (black arrow) were composed of cells with clear cytoplasm and oval-to-fusiform nuclei. $\mathbf{d}$ The polygonal and spindle cells (black arrow head) were similar to the outer-layer cells (black arrow) and had clear cytoplasm 


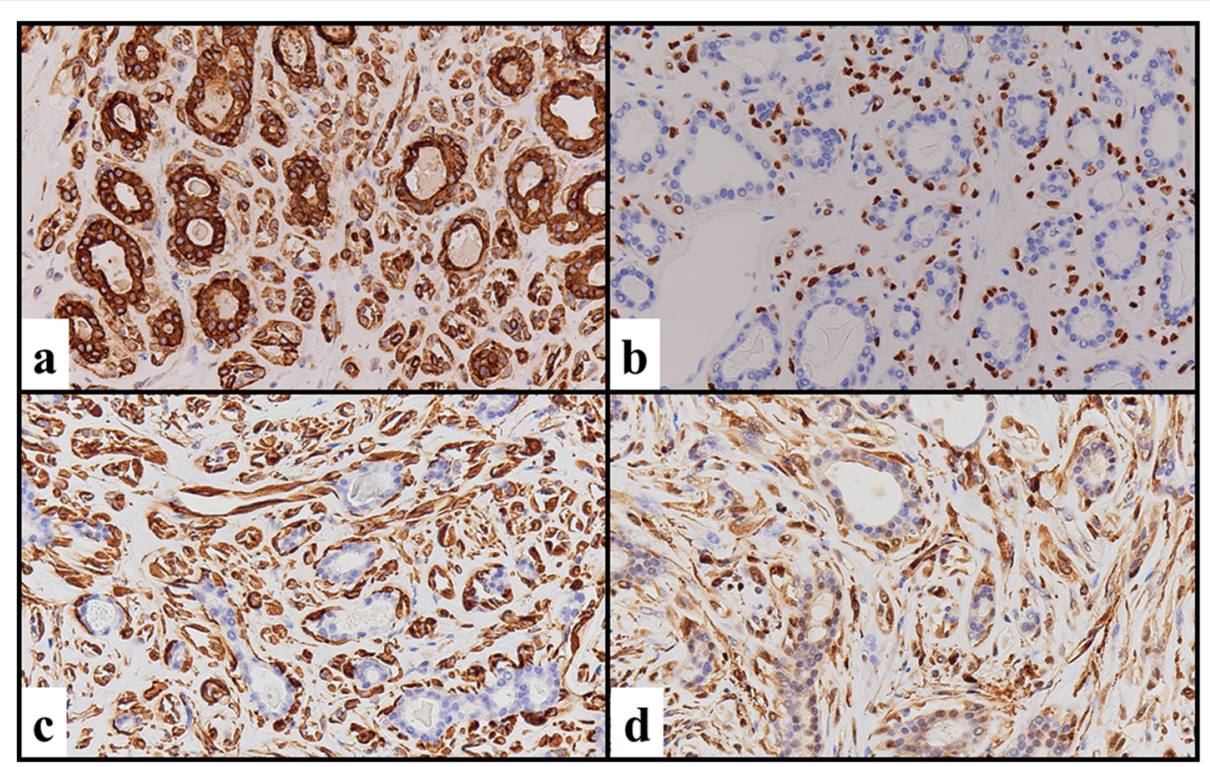

Fig. 3 Immunohistochemical findings. a The cuboidal cells in the inner layer were positive for pan-cytokeratin (cytoplasm), and the outer layer of cells and polygonal and spindle cells were weakly positive for pan-cytokeratin (cytoplasm). b-d The cuboidal cells in the inner layer were negative for p63 (b), HHF35 (c) and S-100 (d), whereas the outer layer of cells and polygonal and spindle cells were positive for p63 (nucleus) (b), HHF35 (cytoplasm) (c) and S-100 (nucleus and cytoplasm) (d)

extracted using TaKaRa DEXPAT (Takara Bio Inc., Shiga, Japan). The tumor component on the slides was microdissected to increase the tumor cell proportion. The PCR products were purified using the NucleoSpin Gel and PCR Clean-up, Mini kit (Marcherey-Nagel, Duren, Germany). Each purified product was directly sequenced using a forward primer and the BigDye Terminator version 3.1 cycle sequencing kit on the $\mathrm{ABI}$ 3730 instrument (Applied Biosystems Inc., Foster City, CA). Mutation analyses of AKT1 (exon 2), CTNNB1 (exon 3), HRAS (exons 2 and 3) and PIK3CA (exons 9 and 20) were performed based on the method described by Urano et al. [7]. The primer sequences are listed in Table 1 . In addition, mutation analyses of $B R A F$ (exon 15 ) and $K R A S$ (exons 2 and 3 ) were performed using the BRAF Pyro Kit and KRAS Pyro Kit (Qiagen, Venlo, Netherlands), respectively, in real-time using pyrosequencing technology on the PyroMark Q24 System (Qiagen). No mutation in any of the six genes was detected.

\section{Discussion}

EMC is a rare malignant salivary gland tumor that accounts for $<1 \%$ of all salivary gland epithelial neoplasms and nearly $2 \%$ of malignant salivary gland tumors $[1,8]$. EMC of the salivary gland was first described by Donath et al. in 1972 [9]. EMC is characterized by a biphasic morphology, with an inner layer of duct-like structures composed of epithelial cells and a surrounding layer of myoepithelial cells immunoreactive for S-100 and smooth muscle actin $[1,2,6]$. The tracheobronchial glands are considered counterparts of the minor salivary glands in the respiratory tract and can develop similar tumors. Within this type of neoplasia, EMC of the respiratory tract is very rare, and the diagnosis is often difficult $[10,11]$. Salivary gland-type tumors of the lung account for $0.1-1 \%$ of all primary lung carcinomas, among which mucoepidermoid carcinoma is the most frequently observed histological subtype, followed by adenoid cystic carcinoma and then EMC [4, 5]. Recently, Nakashima et al. conducted a literature review of 56 patients (32 females and 24 males; average age [range], 56 [7-81] years) with pulmonary EMC [6]. Of these, 45

Table 1 PCR primers used for Sanger sequencing

\begin{tabular}{lll}
\hline Gene & Direction & Sequence (5' to 3') \\
\hline AKT1 exon 2 & Forward & AGGCACATCTGTCCTGGCAC \\
& Reverse & AAATCTGAATCCCGAGAGGCC \\
CTNNB1 exon 3 & Forward & TTGATGGAGTTGGACATGG \\
& Reverse & AAAATCCCTGTTCCCACTCA \\
HRAS exon 2 & Forward & CAGGCCCCTGAGGAGCGATG \\
& Reverse & TTCGTCCACAAAATGGTCT \\
HRAS exon 3 & Forward & TCCTGCAGGATTCCTACCGG \\
& Reverse & GGTTCACCTGTACTGGTGGGA \\
PIK3CA exon 9 & Forward & TGACAAAGAAGAGCTCAAAGC \\
& Reverse & TTAGCACTTACCTGTGACTCCA \\
PIK3CA exon 20 & Forward & TGATGACATTGCATACATTCG \\
& Reverse & TGTGTGGAAGATCCAATCCA \\
\hline
\end{tabular}


patients had tumors localized in the central airway within segmental bronchi appearing to be endobronchial masses. The size of the tumors varied from 0.7 to $16 \mathrm{~cm}$ in diameter (average $2.5 \mathrm{~cm}$ ). According to the histopathological characteristics, three distinct histological subtypes of pulmonary EMC were reported: (1) EMC with two ductal components, defined as a characteristic feature of this tumor, (2) EMC with a solid component consisting mainly of spindle- and polygonal-shaped myoepithelial cells, and (3) EMC consisting mainly of myoepithelial cells with increased nuclear atypia, referred to as myoepithelial anaplasia $[6,12-14]$. Seethala et al. reported that patients with myoepithelial anaplasia had a poorer survival compared with others [15]. Although our case was diagnosed as adenocarcinoma in the small biopsy, it proved to be typical EMC featuring two ductal components and immunohistochemically.

Several genetic mutations have been detected in EMC of the salivary glands [7, 16, 17]; HRAS mutations are the most frequently detected, followed by PIK3CA and AKT1 mutations. The genetic alterations associated with pulmonary EMC are still unknown because of the rarity of this tumor. Urano et al. are the only ones who described HRAS mutations in all three pulmonary EMC that they analyzed [7]. However, our case did not show any mutations in AKT1, HRAS or PIK3CA. Although the number of reported cases is very small, the frequency of HRAS mutations in pulmonary EMC is $75 \%$ (3/4 cases). At this time, we cannot conclude whether the genetic alterations in pulmonary EMC are similar to those of other EMC types. Typical cases of pulmonary EMC are easy to diagnose, whereas atypical cases can be difficult to distinguish. Furthermore, because the biopsy specimen is small, the duct-like structure may be misdiagnosed as adenocarcinoma. Determination of the characteristic gene mutations will be useful for differentiating pulmonary EMC from other salivary gland tumors of the lung.

In conclusion, we report a case of pulmonary EMC containing no AKT1, HRAS, or PIK3CA mutations. Further examinations will be needed.

\section{Abbreviations}

EMC: Epithelial-myoepithelial carcinoma; PCR: Polymerase chain reaction

\section{Acknowledgements}

The authors would like to thank Ms. E. Sugawara and Ms. C. Ishikawa for their technical assistance, as well as the members of the Department of Molecular Diagnostic Pathology, Iwate Medical University, for their support.

\section{Authors' contributions}

NY and TS: conception and writing of manuscript. NY and HS: collection of clinical data. NY, AS, KN, MS, RS, MO and NU: pathological diagnosis and immunohistochemical analyses. NY: collection of the samples for the molecular analyses. NY, HS and TS: revision of the manuscript. All authors read and approved the final manuscript prior to submission.

\section{Funding}

The authors have no funding to disclose.

\section{Availability of data and materials}

The datasets used and/or analyzed during the current study are available from the corresponding author upon reasonable request.

Ethics approval and consent to participate

Not applicable.

\section{Consent for publication}

Written informed consent was obtained from the patient for the publication of this case report.

\section{Competing interests}

The authors declare that they have no competing interests.

\section{Author details}

'Department of Molecular Diagnostic Pathology, Iwate Medical University, 2-1-1 Idaidori, Yahaba-cho, Shiwa-gun, Iwate 0283695, Japan. ${ }^{2}$ Department of Thoracic Surgery, Iwate Medical University, Yahaba-cho, Shiwa-gun, Iwate 0283695, Japan.

Received: 24 June 2020 Accepted: 21 August 2020

Published online: 28 August 2020

\section{References}

1. Seethala R, Bell D, Fonseca I, et al. Epithelial-myoepithelial carcinoma. In: ElNaggar A, Chan JK, Grandis J, Takata T, Slootweg P, editors. WHO classification of head and neck tumours. Lyon: International Agency for Research on Cancer; 2017. p. 309-22.

2. Ishikawa Y, Dacic S, Husain AN, Nicholson AG. Epithelial-myoepithelial carcinoma. In: Travis WD, Brambilla E, Burke AP, editors. World Health Organization classification of tumours of the lung, pleura, thymus and heart. 4th ed. Lyon: International Agency for Research on Cancer Press; 2015. p. 103-4.

3. Singh G, Sharma MC, Agarwal S, Prasad GL, Mishra S, Singh MM, et al. Epithelial myoepithelial carcinoma of the lacrimal gland: a rare case. Ann Diagn Pathol. 2012;16:292-7.

4. Kang D-Y, Yoon YS, Kim HK, Choi YS, Kim K, Shim YM, et al. Primary salivary gland-type lung cancer: surgical outcomes. Lung Cancer. 2011;72:250-4.

5. Zhu F, Liu Z, Hou Y, He D, Ge X, Bai C, et al. Primary salivary gland-type lung cancer clinicopathological analysis of 88 cases from China. J Thorac Oncol. 2013:8:1578-84.

6. Nakashima Y, Morita R, Ui A, lihara K, Yazawa T. Epithelial-myoepithelial carcinoma of the lung: a case report. Surg Case Rep. 2018;4:1-8.

7. Urano M, Nakaguro M, Yamamoto Y, Hirai H, Tanigawa M, Saigusa N, et al. Diagnostic significance of HRAS mutations in epithelial-myoepithelial carcinomas exhibiting a broad histopathologic spectrum. Am J Surg Pathol. 2019:43:984-94.

8. Ellis GL, Auclair P. Epithelial-myoepithelial carcinoma. Tumors of the salivary glands (AFIP Atlas of Tumor Pathology: series 4). Washington, DC: American Registry of Pathology; 2008. p. 309-22.

9. Donath K, Seifert G, Schmitz R. [Diagnosis and ultrastructure of the tubular carcinoma of salivary gland ducts. Epithelial-myoepithelial carcinoma of the intercalated ducts]. Virchows arch a. Pathol Pathol Anat. 1972;356:16-31.

10. Konoglou M, Cheva A, Zarogoulidis P, Porpodis K, Pataka A, Mpaliaka A, et al. Epithelial-myoepithelial carcinoma of the trachea-a rare entity case report. J Thorac Dis. 2014;6(Suppl 1):S194-9.

11. Shen C, Wang X, Che G. A rare case of primary peripheral epithelial myoepithelial carcinoma of lung: Case report and literature review. Medicine (Baltimore). 2016;95:e4371. https://doi.org/10.1097/MD. 0000000000004371.

12. Moran CA, Suster S, Askin FB, Koss MN. Benign and malignant salivary gland-type mixed tumors of the lung. Clinicopathologic and immunohistochemical study of eight cases. Cancer. 1994;73:2481-90.

13. Cha YJ, Han J, Lee MJ, Lee KS, Kim H, Zo J. A rare case of bronchial epithelial-myoepithelial carcinoma with solid lobular growth in a 53-yearold woman. Tuberc Respir Dis (Seoul). 2015;78:428-31.

14. Tajima S, Aki M, Yajima K, Takahashi T, Neyatani H, Koda K. Primary epithelial-myoepithelial carcinoma of the lung: a case report 
demonstrating high-grade transformation-like changes. Oncol Lett. 2015; 10:175-81.

15. Seethala RR, Barnes EL, Hunt JL. Epithelial-myoepithelial carcinoma: a review of the clinicopathologic spectrum and immunophenotypic characteristics in 61 tumors of the salivary glands and upper aerodigestive tract. Am J Surg Pathol. 2007;31:44-57.

16. Chiosea SI, Miller M, Seethala RR. HRAS mutations in epithelial-myoepithelial carcinoma. Head Neck Pathol. 2014;8:146-50.

17. El Hallani S, Udager AM, Bell D, Fonseca I, Thompson LDR, Assaad A, et al. Epithelial-myoepithelial carcinoma: frequent morphologic and molecular evidence of preexisting pleomorphic adenoma, common HRAS mutations in PLAG1-intact and HMGA2-intact cases, and occasional TP53, FBXW7, and SMARCB1 alterations in high-grade cases. Am J Surg Pathol. 2018;42:18-27.

\section{Publisher's Note}

Springer Nature remains neutral with regard to jurisdictional claims in published maps and institutional affiliations.

Ready to submit your research? Choose BMC and benefit from:

- fast, convenient online submission

- thorough peer review by experienced researchers in your field

- rapid publication on acceptance

- support for research data, including large and complex data types

- gold Open Access which fosters wider collaboration and increased citations

- maximum visibility for your research: over $100 \mathrm{M}$ website views per year

At $\mathrm{BMC}$, research is always in progress.

Learn more biomedcentral.com/submissions 